STRUCTURAL BIOLOGY COMMUNICATIONS

ISSN 2053-230X

Received 7 June 2016

Accepted 25 August 2016

₹ These authors contributed equally to this paper.

Keywords: phospholipid hydroperoxide glutathione peroxidase 4 ; reactive oxidative species; NMR spectroscopy; small-angle X-ray scattering.

PDB reference: GPx4, 5171

Supporting information: this article has supporting information at journals.iucr.org/f

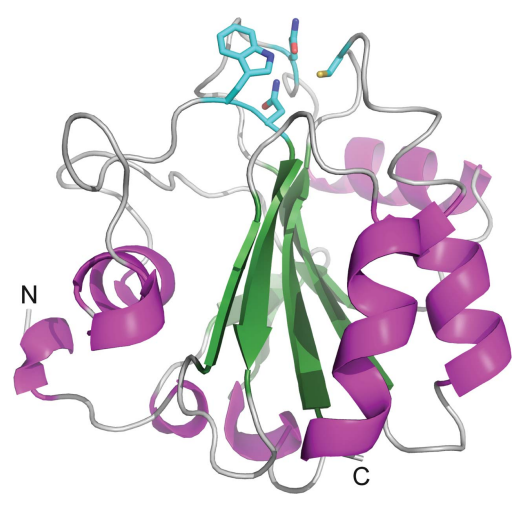

OPEN $\odot$ ACCESS

\section{Crystal and solution structural studies of mouse phospholipid hydroperoxide glutathione peroxidase 4}

\author{
Robert Janowski, ${ }^{a} \neq$ Sandra Scanu, ${ }^{\mathrm{b}, \mathrm{c}} \neq$ Dierk Niessing ${ }^{\mathrm{a}, \mathrm{d} *}$ and Tobias Madl ${ }^{\mathrm{b}, \mathrm{c}, \mathrm{e} *}$ \\ ${ }^{a}$ Group Intracellular Transport and RNA Biology, Institute of Structural Biology, Helmholtz Zentrum München - \\ German Research Center for Environmental Health, Ingolstädter Landstrasse 1, 85764 Neuherberg, Germany, ${ }^{\mathbf{b}}$ Institute of \\ Structural Biology, Helmholtz Zentrum München - German Research Center for Environmental Health, Ingolstädter \\ Landstrasse 1, 85764 Neuherberg, Germany, ' Department of Chemistry, Technische Universität München, \\ Lichtenbergstrasse 4, 85748 Garching, Germany, 'Department of Cell Biology at the Biomedical Center, \\ Ludwig-Maximilians-Universität München, Grosshaderner Strasse 9, 82152 Munich, Germany, and $\mathbf{e}$ Institute of \\ Molecular Biology and Biochemistry, Center of Molecular Medicine, Medical University of Graz, Harrachgasse 21/III, \\ 8010 Graz, Austria. *Correspondence e-mail: niessing@helmholtz-muenchen.de, tobias.madl@medunigraz.at
}

The mammalian glutathione peroxidase (GPx) family is a key component of the cellular antioxidative defence system. Within this family, GPx4 has unique features as it accepts a large class of hydroperoxy lipid substrates and has a plethora of biological functions, including sperm maturation, regulation of apoptosis and cerebral embryogenesis. In this paper, the structure of the cytoplasmic isoform of mouse phospholipid hydroperoxide glutathione peroxidase (O70325-2 GPx4) with selenocysteine 46 mutated to cysteine is reported solved at $1.8 \AA$ resolution using X-ray crystallography. Furthermore, solution data of an isotope-labelled GPx protein are presented.

\section{Introduction}

The mammalian glutathione peroxidase (GPx) family is a key component of the cellular antioxidative defence system (Burk \& Hill, 1993). Its eight members (GPx1-GPx8) catalyse the reduction of reactive oxidative species (ROS) such as hydrogen peroxide $\left(\mathrm{H}_{2} \mathrm{O}_{2}\right)$ or other alkyl hydroperoxides at the expense of reduced glutathione and/or other reductants (Burk \& Hill, 1993; Tosatto et al., 2008; Toppo et al., 2008; Brigelius-Flohé \& Maiorino, 2013). This enzymatic reaction involves either a cysteine or a selenocysteine as part of the catalytic tetrad.

GPx4 was first identified in pig liver (Ursini et al., 1982) and has unique features among other members of the GPx family: it accepts a large class of hydroperoxy lipid substrates (Thomas et al., 1990), shows a strong tendency for polymerization (Brigelius-Flohé, 1999; Imai \& Nakagawa, 2003; Ursini et al. 1999) and has several biological functions (Imai \& Nakagawa, 2003; Sattler et al., 1994), including sperm maturation (Ursini et al., 1999; Ingold et al., 2015), regulation of apoptosis (Nomura et al., 1999) and cerebral embryogenesis (Borchert et al., 2006).

The protein is expressed at low levels in most mammalian tissues, with larger amounts present in the testis (BrigeliusFlohé, 1999). Tissue-specific depletion of GPx4 results in several phenotypes in mice, including severe neurodegeneration and seizures (Seiler et al., 2008; Wirth et al., 2010), multiorgan thrombus formation (Wortmann et al., 2013), as well as epidermal hyperplasia, dermal inflammatory infiltrate, dysmorphic hair follicles and alopecia (Sengupta et al., 2013). 
Table 1

Mouse GPx4 production information.

\begin{tabular}{ll}
\hline Source organism & $\begin{array}{c}\text { Mus musculus (mouse), cytoplasmic } \\
\text { isoform O70325-2 } \\
\text { ANA source }\end{array}$ \\
ATG:biosynthetics GmbH \\
Forward primer & N/A \\
Reverse primer & N/A \\
Cloning vector & pUC57 \\
Expression vector & pETM-11 \\
Expression host & E. coli BL21 (DE3) \\
Complete amino-acid sequence & MGCASRDDWRCARSMHEFSAKDIDGHMVCLDKYR- \\
of the construct produced $\dagger$ & GFVCIVTNVASQCGKTDVNYTQLVDLHARYAE- \\
& CGLRILAFPCNQFGRQEPGSNQEIKEFAAGYN- \\
& VKFDMYSKICVNGDDAHPLWKWMKVQPKGRGM- \\
& LGNAIKWNFTKFLIDKNGCVVKRYGPMEEPQV- \\
& IEKDLPCYL
\end{tabular}

$\dagger$ In this construct, selenocysteine 46 (underlined) was mutated to cysteine. The glycine residue in italics is a cloning artefact.

Low testicular levels of GPx4 or expression of GPx4 singlepoint mutants are related to male infertility (Ingold et al., 2015; Imai et al., 2001). Very recently, GPx4 has been identified as a key regulator in a novel type of non-apoptotic cell death termed ferroptosis (Yang et al., 2014; Friedmann Angeli et al., 2014). However, most of the underlying molecular mechanisms remain enigmatic.

Among the three different isoforms present in nature, the 170-residue, $19.5 \mathrm{kDa}$ monomeric cytosolic isoform is essential (Ho et al., 1997). Its key feature is the catalytically active tetrad containing selenocysteine (Sec46), glutamine (Gln81), tryptophan (Trp136) and asparagine (Asn137) (Scheerer et al., 2007; Tosatto et al., 2008). Therein, Sec46 is activated and stabilized by Gln81 and Trp136 through a network of hydrogen bonds (Aumann et al., 1997; Maiorino et al., 1995), whereas the main role of Asn137 appears to be primarily in the initial oxidation step (Tosatto et al., 2008).

With the crystallization of the human GPx4 selenocysteineto-cysteine single-point mutant, the first insights into the unique properties of GPx4 were obtained (Scheerer et al., 2007; PDB entries 2gs3 and 2obi). Nevertheless, given that most in vivo studies on the role of GPx4 in ROS regulation and its interaction network are currently carried out in mouse models, it is of advantage to obtain structural information for the mouse orthologue as well. Furthermore, it would be beneficial to complement the X-ray crystallographic studies of GPx4 with solution studies of the protein, for example by NMR spectroscopy and/or small-angle scattering, in order to set the stage for structural studies with ligands that might be difficult to co-crystallize and to obtain information on protein dynamics that possibly play an important role in GPx4 enzymatic activity (Goodey \& Benkovic, 2008; Schnell et al., 2004; Loria et al., 2008). In this respect, it is noteworthy that no comprehensive solution NMR spectroscopic studies of glutathione peroxidases have been reported to date.

Here, we present a study of the expression, purification and determination of the crystal structure of the selenocysteine 46 to cysteine (U46C) mutant of mouse GPx4. We compare this structure with the previously published structures of human GPx4 (Scheerer et al., 2007; PDB entries 2gs3 and 2obi) and present solution NMR spectra of isotope-labelled protein for the first time. Furthermore, we present small-angle X-ray scattering (SAXS) data indicating that GPx4 is monomeric in solution under reducing conditions. Our data comprehensively describe the three-dimensional structure of the mouse enzyme to $1.8 \AA$ resolution and demonstrate that more extensive solution studies of the enzyme focusing on protein dynamics and GPx4-ligand interactions will be possible in the future. Furthermore, our solution data indicate that the strong tendency of GPx4 for polymerization is likely to be mediated by intermolecular disulfide-bond formation.

\section{Materials and methods}

\subsection{Macromolecule production}

The construct corresponding to the Met1-Leu170 (GPx4) region of mouse cytosolic phospholipid hydroperoxide glutathione peroxidase (O70325-2) with selenocysteine 46 mutated to cysteine was purchased from ATG:biosynthetics $\mathrm{GmbH}$ in a pUC cloning vector. The DNA sequence was codon-optimized for protein production in bacterial cells and flanked by NcoI and BamHI restriction sites. The coding region was cloned into a modified pETM-11 bacterial expression vector (kindly provided by Arie Geerlof, Protein Expression and Purification Facility, Helmholtz Zentrum München, Germany) which was derived from a pET-24d(+) vector (Novagen) by insertion of a Tobacco etch virus (TEV) protease cleavage site following an $\mathrm{N}$-terminal hexahistidine and protein A tag. The GPx4 gene was amplified by PCR using T4 primers (New England Biolabs). The resulting PCR products and pETM-11 were double-digested with $\mathrm{NcoI}$ and BamHI enzymes (New England Biolabs) before ligation. The construct was verified by sequencing. For cloning purposes, a glycine residue was introduced between Met1 and Cys2. The amino-acid residue numbering of GPx4 corresponds to the full-length protein.

Uniformly $\left({ }^{13} \mathrm{C},{ }^{15} \mathrm{~N}\right)$ double-labelled $\mathrm{GPx} 4$ was produced in freshly transformed Escherichia coli DE3 cells. A single colony was inoculated in $20 \mathrm{ml}$ Luria-Bertani medium with $25 \mathrm{mg} \mathrm{l}^{-1}$ kanamycin and cultured at $37^{\circ} \mathrm{C}$ until the $\mathrm{OD}_{600}$ reached 1.0. From this, an aliquot $(1 \mathrm{ml})$ was added to $\left({ }^{13} \mathrm{C},{ }^{15} \mathrm{~N}\right.$-labelled) M9 minimal medium $(100 \mathrm{ml})$ in which ${ }^{15} \mathrm{~N}-\mathrm{NH}_{4} \mathrm{Cl}\left(2 \mathrm{~g} \mathrm{l}^{-1}\right)$ and ${ }^{13} \mathrm{C}$-glucose $\left(3 \mathrm{~g} \mathrm{l}^{-1}\right)$ were the only sources of nitrogen and carbon for NMR isotope-labelling purposes, respectively (Cambridge Isotope Laboratories). The culture was incubated overnight at $37^{\circ} \mathrm{C}$ and shaken at $200 \mathrm{rev} \min ^{-1}$. Fresh $\left({ }^{13} \mathrm{C},{ }^{15} \mathrm{~N}\right)$ M9 minimal medium was added to 11 and the culture was grown under the same conditions until the $\mathrm{OD}_{600}$ reached 1.0. Protein expression was induced with $1 \mathrm{~m} M$ isopropyl $\beta$-D-1-thiogalactopyranoside at $20^{\circ} \mathrm{C}$. The cells were pelleted after $4 \mathrm{~h}$ by centrifugation using a Fiberlite F9-6×1000 rotor in a Sorvall LYNX 6000 Superspeed centrifuge at $2000 \mathrm{~g}$ for $20 \mathrm{~min}$, resuspended in $40 \mathrm{ml}$ lysis buffer consisting of $50 \mathrm{mM} \mathrm{NaH} \mathrm{PO}_{4}, 300 \mathrm{mM} \mathrm{NaCl}$, $10 \mathrm{~m} M$ imidazole, $1 \mathrm{~m} M$ tris(2-carboxyethyl)phosphine (TCEP) $\mathrm{pH}$ 8.0, $2.5 \mu \mathrm{g} \mathrm{ml}^{-1}$ DNase, $1 \mathrm{mg} \mathrm{ml}^{-1}$ lysozyme and protease-inhibitor mix (Serva). Note that the addition of TCEP was essential to avoid protein precipitation. Gpx4 is 
Table 2

Crystallization of GPx4.

\begin{tabular}{ll}
\hline Method & Spontaneous crystallization \\
Plate type & $1.5 \mathrm{ml}$ reaction tube \\
Temperature $(\mathrm{K})$ & 293 \\
Protein concentration $\left(\mathrm{mg} \mathrm{ml}^{-1}\right)$ & 2 \\
Buffer composition of protein solution & $100 \mathrm{~m} M$ MES, $5 \mathrm{~m} M$ TCEP pH 6.5 \\
Composition of reservoir solution & None \\
Volume and ratio of drop & N/A \\
Volume of reservoir & N/A \\
\hline
\end{tabular}

unstable in the reducing agents dithiothreitol and $\beta$-mercaptoethanol. Cell lysis was performed by sonication for $10 \mathrm{~min}$ at $70 \%$ power with $0.5 \mathrm{~Hz}$ cycles (Sonopuls, Bandelin). The cell lysate was separated by ultracentrifugation using a Thermo Scientific SS-34 rotor in a Sigma 6K15 centrifuge at $20000 g$ for $45 \mathrm{~min}$ at $4{ }^{\circ} \mathrm{C}$ and histidine-tagged GPx 4 was affinity-purified via Ni-NTA resin (Qiagen). TEV protease $\left(5 \mu \mathrm{g} \mathrm{ml}^{-1}\right)$ was added to the eluate and dialysed overnight at $4{ }^{\circ} \mathrm{C}$ against $50 \mathrm{~m} M \mathrm{NaH}_{2} \mathrm{PO}_{4}, 300 \mathrm{~m} M \mathrm{NaCl}, 10 \mathrm{~m} M$ imidazole, $1 \mathrm{~m} M$ TCEP $\mathrm{pH}$ 8.0. The GPx4 fragment was separated from the tag by a second affinity-purification step via Ni-NTA resin. GPx4 was loaded onto a size-exclusion column (Superdex 75 10/300 GL, GE Healthcare) equilibrated with $100 \mathrm{~m} M$ MES, $5 \mathrm{mM}$ TCEP pH 6.5 using an ÄKTA pure FLPC system. The purity was estimated by SDS-PAGE to be $95 \%$, with the yield of pure protein being $5 \mathrm{mg}$ per litre of culture. Macromoleculeproduction information is summarized in Table 1.

\subsection{Small-angle X-ray scattering}

All SAXS data were recorded on an in-house SAXS instrument (SAXSess $\mathrm{mc}^{2}$, Anton Paar) equipped with a Kratky camera, a sealed X-ray tube source and a twodimensional Princeton Instruments PI.SCX:4300 CCD detector (Roper Scientific). The scattering patterns were measured with $180 \mathrm{~min}$ exposure times (1080 frames, each of $10 \mathrm{~s}$ ) for several solute concentrations in the range from 1.75 to $5.0 \mathrm{mg} \mathrm{ml}^{-1}$. Radiation damage was excluded based on a comparison of individual frames of the $180 \mathrm{~min}$ exposures, where no changes were detected. A momentum-transfer range of $0.012<s<0.63 \AA^{-1}$ was covered $[s=4 \pi \sin (\theta) / \lambda$, where $2 \theta$ is the scattering angle and $\lambda=1.542 \AA$ is the X-ray wavelength].

All SAXS data were analysed with $A T S A S$ v.2.5. The data were processed with $S A X S Q$ uant v.3.9 and de-smeared using GNOM (Svergun, 1992) and GIFT (Bergmann et al., 2000). The forward scattering $I(0)$, the radius of gyration $R_{\mathrm{g}}$, the maximum dimension $D_{\max }$ and the interatomic distance distribution function $P(r)$ were computed with GNOM (Svergun, 1992) and GIFT (Bergmann et al., 2000). The masses of the solutes were evaluated by comparison of the forward scattering intensity with that of a human serum albumin reference solution (molecular mass $69 \mathrm{kDa}$ ) and using Porod's law.

To generate $a b$ initio shape models, a total number of 50 models were calculated using DAMMIF (Franke \& Svergun, 2009), aligned, and averaged using DAMCLUST. The ab initio
Table 3

Data collection and processing.

Values in parentheses are for the outer shell.

\begin{tabular}{ll}
\hline Diffraction source & X06SA, SLS \\
Wavelength $(\AA)$ & 0.99999 \\
Temperature $(\mathrm{K})$ & 100 \\
Detector & PILATUS 6M \\
Crystal-to-detector distance $(\mathrm{mm})$ & 320.02 \\
Rotation range per image $\left(^{\circ}\right)$ & 0.1 \\
Total rotation range $\left({ }^{\circ}\right)$ & 140 \\
Exposure time per image (s) & 0.1 \\
Space group & $P 3_{1} 21$ \\
$a, b, c(\AA)$ & $61.26,61.26,113.98$ \\
$\alpha, \beta, \gamma\left({ }^{\circ}\right)$ & $90,90,120$ \\
Mosaicity $\left({ }^{\circ}\right)$ & 0.2 \\
Resolution range $(\AA)$ & $100-1.80(1.85-1.80)$ \\
Total No. of reflections & 175065 \\
No. of unique reflections & 23549 \\
Completeness $(\%)$ & $99.8(99.9)$ \\
Multiplicity & $7.4(7.6)$ \\
$\langle I / \sigma(I)\rangle$ & $21.6(4.09)$ \\
$R_{\text {merge }}(\%)$ & $6.0(70.4)$ \\
$C C_{1 / 2}(\%)$ & 97.7 \\
Overall $B$ factor from Wilson plot $\left(\AA^{2}\right)$ & 29.3 \\
\hline
\end{tabular}

shape models were aligned with the crystal structure of GPx4 determined here using SUPCOMB (Kozin \& Svergun, 2001).

\subsection{NMR spectroscopy}

The two-dimensional ${ }^{1} \mathrm{H},{ }^{15} \mathrm{~N}$ HSQC NMR spectrum of ${ }^{13} \mathrm{C},{ }^{15} \mathrm{~N}$-labelled GPx4 was recorded on a Bruker AV III 900 spectrometer (Bruker, Rheinstetten, Germany) at $25^{\circ} \mathrm{C}$. The NMR buffer used was $100 \mathrm{~m} M$ MES, $5 \mathrm{~m} M$ TCEP pH 6.5, and $5 \% \mathrm{D}_{2} \mathrm{O}$ was added for the field frequency lock. The labelled protein concentration was $100 \mu M$. The NMR spectrum was acquired before the protein crystallized spontaneously in the NMR tube. The NMR spectrum was processed using Bruker TopSpin 3.2.

\subsection{Crystallization}

The GPx4 protein crystallized spontaneously from a solution consisting of $100 \mathrm{~m} M$ MES, $5 \mathrm{~m} M$ TCEP pH 6.5 at a concentration of $2 \mathrm{mg} \mathrm{ml}^{-1}$ at room temperature. Rod-like, long, hexagonal crystals appeared in the $1.5 \mathrm{ml}$ reaction tube. Crystallization information is summarized in Table 2.

\subsection{Data collection and processing}

For the X-ray diffraction experiments, crystals were mounted in a nylon-fibre loop and flash-cooled to $100 \mathrm{~K}$ in liquid nitrogen. Diffraction data for GPx4 were collected on the X06SA beamline at SLS, Villigen, Switzerland using a PILATUS 6M detector at a wavelength of $0.99999 \AA$. The crystal diffracted to $1.8 \AA$ resolution. The data set was indexed and integrated using $X D S$ (Kabsch, 2010) and scaled using SCALA (Evans, 2006; Winn et al., 2011). Intensities were converted to structure-factor amplitudes using TRUNCATE (French \& Wilson, 1978). Table 3 summarizes the datacollection and processing statistics. 
Table 4

Structure solution and refinement.

Values in parentheses are for the outer shell.

\begin{tabular}{ll}
\hline Resolution range $(\AA)$ & $53.050-1.800(1.847-1.800)$ \\
Completeness $(\%)$ & $99.79(99.88)$ \\
$\sigma$ Cutoff & None \\
No. of reflections, working set & $22298(1600)$ \\
No. of reflections, test set & $1251(94)$ \\
Final $R_{\text {cryst }}$ & $0.151(0.216)$ \\
Final $R_{\text {free }}$ & $0.193(0.285)$ \\
No. of non-H atoms & \\
$\quad$ Protein & 1348 \\
$\quad$ Other & 12 \\
$\quad$ Water & 185 \\
R.m.s. deviations & \\
$\quad$ Bonds $(\AA)$ & 0.03 \\
$\quad$ Angles $\left({ }^{\circ}\right)$ & 2.46 \\
Average $B$ factors $\left(\AA^{2}\right)$ & \\
$\quad$ Protein & 37.0 \\
Ramachandran plot & \\
$\quad$ Most favoured $(\%)$ & 99 \\
$\quad$ Allowed $(\%)$ & 1 \\
\hline
\end{tabular}

\subsection{Structure solution and refinement}

The crystals of mouse phospholipid hydroperoxide glutathione peroxidase $(\mathrm{GPx} 4)$ are isomorphous to the previously obtained crystals of the human homologue (PDB entry 2obi; Scheerer et al., 2007). The proteins share $93 \%$ sequence identity. For the correct placement of the human homologue into the crystals of mouse GPx4, we performed molecular replacement with $M O L R E P$ (Vagin \& Teplyakov, 2010) from the CCP4 suite (Winn et al., 2011). Model building was performed in Coot (Emsley et al., 2010). Refinement was performed in REFMAC5 (Murshudov et al., 2011) using the maximum-likelihood target function including TLS parameters (Winn et al., 2001). The final model is characterized

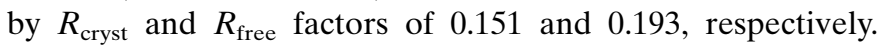
Stereochemical analysis of the model was performed in PROCHECK (Laskowski et al., 1993) and MolProbity (Chen et al., 2010). It indicated that there are no residues with generously allowed or unfavourable backbone dihedral angles and that $99 \%$ of all residues are in the core region of the Ramachandran plot. The refinement parameters are shown in Table 4. All software was part of the SBGrid software bundle (Morin et al., 2013). Atomic coordinates and structure factors have been deposited in the Protein Data Bank under accession code 5171. Mouse and human GPx4 are isomorphous and show the same crystal packing.

\section{Results and discussion}

We successfully cloned, expressed and purified a fragment from Met1 to Leu170 of the cytoplasmic isoform of mouse GPx4 with selenocysteine 46 mutated to cysteine. Sizeexclusion chromatography experiments indicated a monomeric state of the protein. GPx4 crystallized spontaneously in a $1.5 \mathrm{ml}$ reaction tube at $2 \mathrm{mg} \mathrm{ml}^{-1}$ concentration at room temperature after acquiring the NMR spectrum. We took advantage of this fact and implemented X-ray crystallographic methods to solve the structure of this protein using single- crystal diffraction. To date there is no structure of mouse GPx4 protein available, and only two structures of its human homologue have been deposited in the Protein Data Bank [PDB entries 2obi (Scheerer et al., 2007) and 2gs3 (Structural Genomics Consortium, unpublished work)]. Apart from this there are structures of GPx proteins from other organisms with lower sequence identity (for details see Supplementary Table S1; superposition of the selected structures is shown in Supplementary Fig. S1). For the structure solved in this study at $1.8 \AA$ resolution (Fig. $1 a$ ) the $2 F_{\mathrm{o}}-F_{\mathrm{c}}$ electron-density map is clearly visible for residues Asp6-Leu170. The first six N-terminal residues, Met1, Gly (added for the purposes of cloning) as well as Cys2-Arg5, are not visible owing to

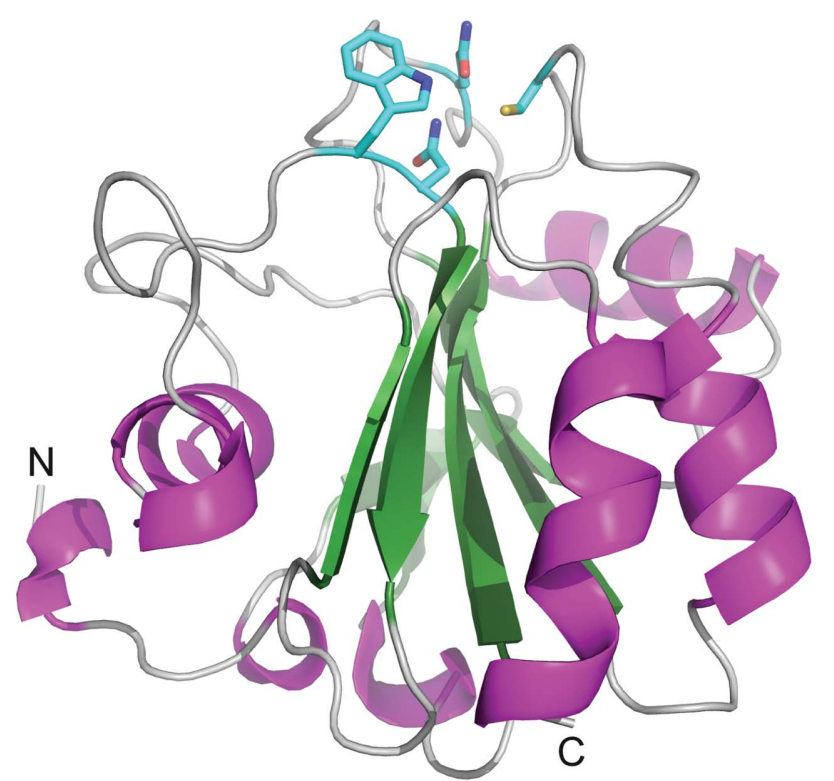

(a)

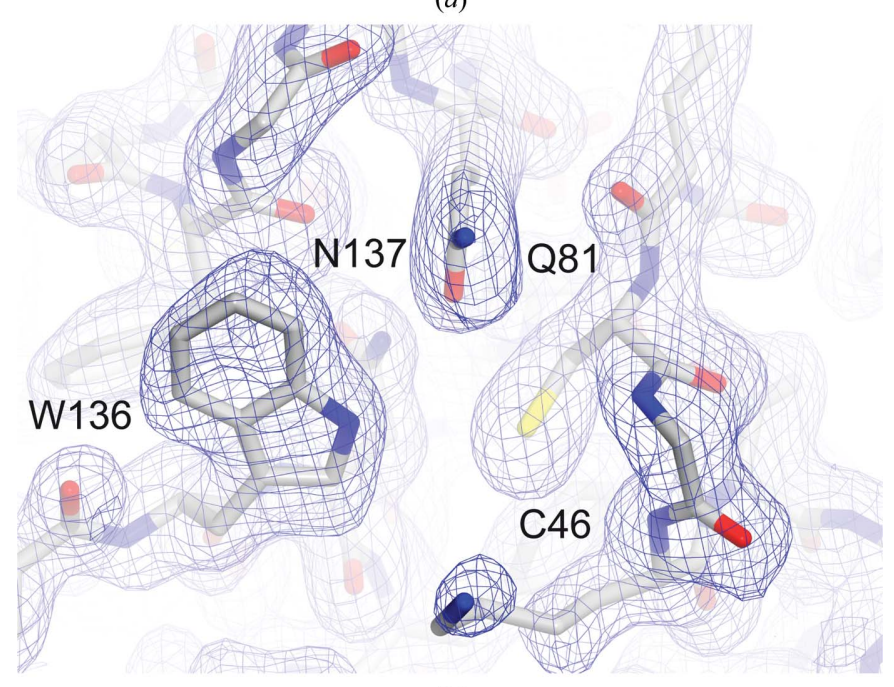

(b)

Figure 1

(a) The overall structure of mouse GPx4 shown as a ribbon. The secondary-structure elements are coloured as follows: helices, magenta; $\beta$-strands, green; loops, grey. The catalytic tetrad, located at the top of the structure, is shown in cyan. $(b)$ shows a $2 F_{\mathrm{o}}-F_{\mathrm{c}}$ electron-density map contoured at $1 \sigma$ for the catalytic tetrad residues. $(a)$ and $(b)$ were prepared using PyMOL (v.1.8; Schrödinger) and CueMol (http:// www.cuemol.org/en), respectively. 
disorder. Overall, the mouse GPx4 has the same fold as its human homologue. With a root-mean-square deviation (r.m.s.d.) of $0.21 \AA$ for 165 superimposed $\mathrm{C}^{\alpha}$ atoms, the structures can be considered to be isomorphous. They consist of four $\alpha$-helices and several helical turns forming the surface of the protein, as well as seven $\beta$-strands organized in a mixed parallel and antiparallel manner forming the core of the structure (mouse GPx4 is shown in Fig. 1a). The active site of the GPx4 enzyme consists of the catalytic tetrad Sec46, Gln81, Trp136 and Asn137. In this study selenocysteine 46 was mutated to cysteine. The active site is located at the top of the structure in the orientation presented in Fig. 1(a). A close-up of the tetrad is presented in Fig. 1(b) and Supplementary Fig. S2 (a). The active-site cavity is surrounded by a number of positively charged amino-acid residues (Lys48, Arg80 and Lys135; Supplementary Fig. S2b). All of the cysteine residues are in the reduced form.

Functioning as a structural protein, GPx4 appears to be involved in the formation of the mitochondrial capsule during sperm development. For this function, the formation of high- molecular-mass polymers has been reported to be important (Ursini et al., 1999). Given that GPx4 contains several cysteine residues, this raises the question whether polymerization is mediated by intermolecular disulfide-bond formation or whether other intermolecular interactions mediate these interactions. To test whether GPx4 polymerization occurs in solution under reducing conditions, we carried out small-angle X-ray scattering (SAXS) and NMR spectroscopic analysis. Scattering curves recorded at several solute concentrations showed that GPx4 is monomeric in solution, as indicated by an apparent molecular mass of $20 \mathrm{kDa}$ (calculated molecular mass of $20 \mathrm{kDa})$, an $R_{\mathrm{g}}$ of $16.8 \AA$ (16.5 ̊ calculated from the X-ray structure) and a $D_{\max }$ of $50 \AA$ (the corresponding dimension in the model of the crystal structure is $50 \AA$; Figs. $2 a$ and $2 b$, Supplementary Fig. S3). Experimental scattering data and a SAXS-based de novo structural model are in excellent agreement with scattering data back-calculated from the crystal structure determined here $\left(\chi^{2}=1.1\right)$. We acquired a two-dimensional heteronuclear single-quantum coherence (HSQC) NMR spectrum of uniformly ${ }^{13} \mathrm{C},{ }^{15} \mathrm{~N}$-labelled Gpx4.

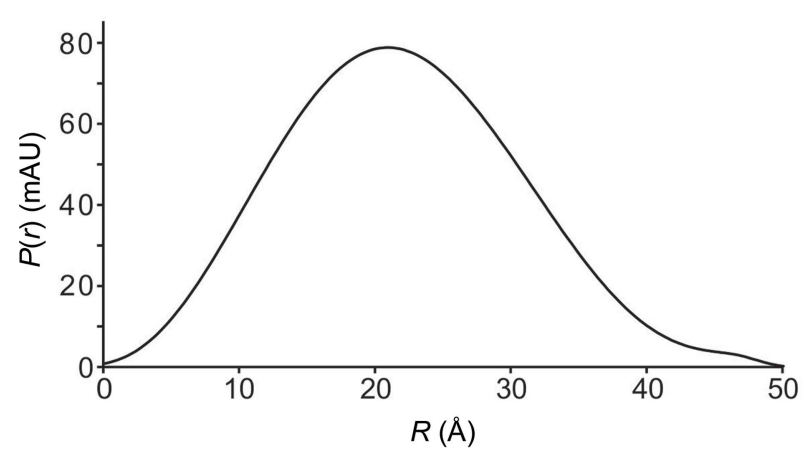

(a)

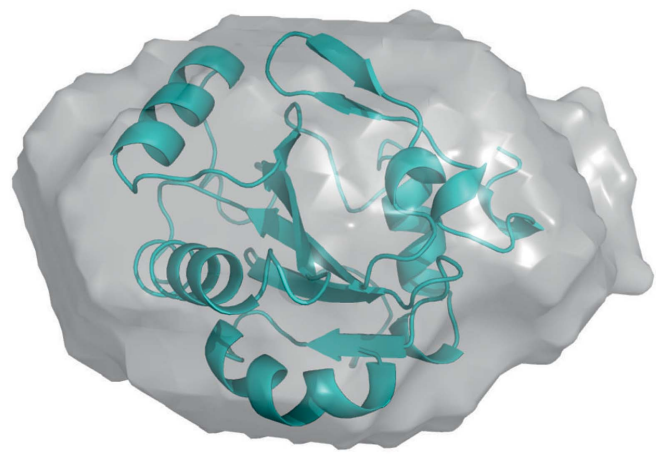

(b)

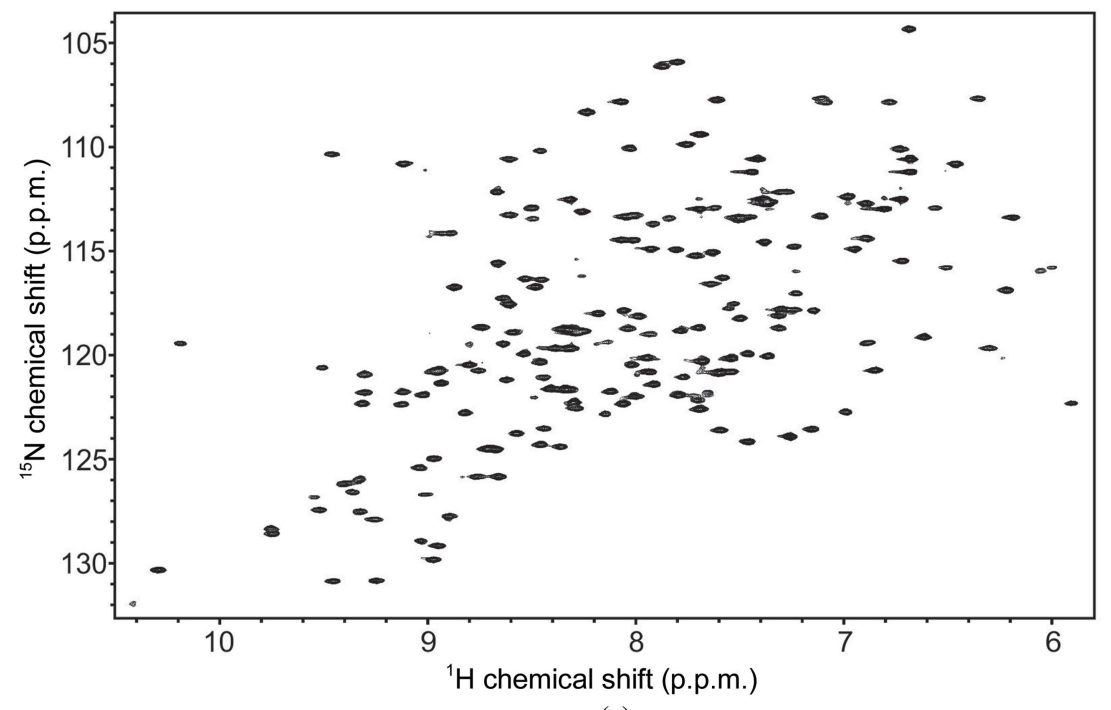

(c)

Figure 2

(a) The SAXS-based experimental radial density distribution shows that GPx4 adopts a compact conformation in solution. The following SAXS-based parameters have been derived: an apparent molecular mass of $20 \mathrm{kDa}$ (calculated, $20 \mathrm{kDa}$ ), an $R_{\mathrm{g}}$ of $16.8 \AA$ ( $16.5 \AA$ calculated from the X-ray structure), $D_{\max }$ of $50 \AA$ (50 $\AA$ in the crystal structure model), agreement of experimental scattering data with scattering data back-calculated from the crystal structure $\chi^{2}=1.1$. (b) Overlay of the SAXS ab initio model with the GPx4 crystal structure determined here. The model was calculated by $D A M M I F$ using an average of 50 structures $\left(R_{\mathrm{f}}=0.0032\right)$. The figure was prepared using PyMOL. (c) Two-dimensional ${ }^{1} \mathrm{H},{ }^{15} \mathrm{~N}$ HSQC NMR spectrum of ${ }^{13} \mathrm{C},{ }^{15} \mathrm{~N}$ labelled GPx4. The excellent dispersion and quality of the NMR resonances are as expected for a well folded $20 \mathrm{kDa}$ protein and indicate that GPx4 is monomeric in solution. The spectrum was recorded with 16 scans, an inter-scan delay of $1 \mathrm{~s}$ and 256 complex points in the indirect dimension. 
This method provides a fingerprint of all amide bonds of a protein, which allows mapping of the protein structure and dynamics with single-residue resolution. In line with the SAXS data, two-dimensional ${ }^{1} \mathrm{H},{ }^{15} \mathrm{~N}$ HSQC NMR data recorded on ${ }^{13} \mathrm{C},{ }^{15} \mathrm{~N}$ isotope-labelled protein shows well resolved narrow NMR resonances, indicating that the protein is well folded and monomeric (Fig. 2c). The formation of a GPx4 dimer or higher oligomers would be visible in form of extensive line broadening and disappearance of NMR signals and can be excluded.

In summary, with $93 \%$ sequence identity the structures of mouse and human GPx4 are isomorphous. Our solution data further show that mouse GPx4 is monomeric under reducing conditions. Furthermore, our solution NMR and SAXS studies demonstrate that more extensive solution studies of the enzyme focusing on protein dynamics and GPx4-ligand interactions will be feasible in the future.

\section{Related literature}

The following references are cited in the Supporting Information for this article: Crow et al. (2004), Dimastrogiovanni et al. (2010), Gabrielson et al. (2012), Hall et al. (2009), Koh et al. (2007) and Krissinel \& Henrick (2004).

\section{Acknowledgements}

We acknowledge the use of the X-ray crystallography platform of the Helmholtz Zentrum München. DN was supported by the Deutsche Forschungsgemeinschaft (FOR 2333, SPP1935 and SFB646), TM was supported by the Bavarian Ministry of Sciences, Research and the Arts (Bavarian Molecular Biosystems Research Network), the Deutsche Forschungsgemeinschaft [Emmy Noether program MA 5703/1-1, Excellence Initiative Center for Integrated Protein Science Munich (CIPSM)], the Austrian Science Fund (FWF; P28854, DKMCD W1226) and the PhD programme 'Molecular Medicine' of the Medical University of Graz. We acknowledge C. Göbl and C. Hartlmüller for help with the SAXS measurements.

\section{References}

Aumann, K. D., Bedorf, N., Brigelius-Flohé, R., Schomburg, D. \& Flohé, L. (1997). Biomed. Environ. Sci. 10, 136-155.

Bergmann, A., Fritz, G. \& Glatter, O. (2000). J. Appl. Cryst. 33, 12121216.

Borchert, A., Wang, C. C., Ufer, C., Schiebel, H., Savaskan, N. E. \& Kuhn, H. (2006). J. Biol. Chem. 281, 19655-19664.

Brigelius-Flohé, R. (1999). Free Radic. Biol. Med. 27, 951-965.

Brigelius-Flohé, R. \& Maiorino, M. (2013). Biochim. Biophys. Acta, 1830, 3289-3303.

Burk, R. F. \& Hill, K. E. (1993). Annu. Rev. Nutr. 13, 65-81.

Chen, V. B., Arendall, W. B., Headd, J. J., Keedy, D. A., Immormino, R. M., Kapral, G. J., Murray, L. W., Richardson, J. S. \& Richardson, D. C. (2010). Acta Cryst. D66, 12-21.

Crow, A., Acheson, R. M., Le Brun, N. E. \& Oubrie, A. (2004). J. Biol. Chem. 279, 23654-23660.

Dimastrogiovanni, D., Anselmi, M., Miele, A. E., Boumis, G., Petersson, L., Angelucci, F., Di Nola, A., Brunori, M. \& Bellelli, A. (2010). Proteins, 78, 259-270.

Emsley, P., Lohkamp, B., Scott, W. G. \& Cowtan, K. (2010). Acta Cryst. D66, 486-501.
Evans, P. (2006). Acta Cryst. D62, 72-82.

Franke, D. \& Svergun, D. I. (2009). J. Appl. Cryst. 42, 342-346.

French, S. \& Wilson, K. (1978). Acta Cryst. A34, 517-525.

Friedmann Angeli, J. P. et al. (2014). Nature Cell Biol. 16, 1180-1191.

Gabrielsen, M., Beckham, K. S. H., Feher, V. A., Zetterstrom, C. E., Wang, D., Muller, S., Elofsson, M., Amaro, R. E., Byron, O. \& Roe, A. J. (2012). PLoS One, 7, e32217.

Goodey, N. M. \& Benkovic, S. J. (2008). Nature Chem. Biol. 4, 474-482.

Hall, A., Sankaran, B., Poole, L. B. \& Karplus, P. A. (2009). J. Mol. Biol. 393, 867-881.

Ho, Y.-S., Magnenat, J.-L., Bronson, R. T., Cao, J., Gargano, M., Sugawara, M. \& Funk, C. D. (1997). J. Biol. Chem. 272, 1664416651.

Imai, H. \& Nakagawa, Y. (2003). Free Radical Biol. Med. 34, 145169.

Imai, H., Suzuki, K., Ishizaka, K., Ichinose, S., Oshima, H., Okayasu, I., Emoto, K., Umeda, M. \& Nakagawa, Y. (2001). Biol. Reprod. 64, 674-683.

Ingold, I., Aichler, M., Yefremova, E., Roveri, A., Buday, K., Doll, S., Tasdemir, A., Hoffard, N., Wurst, W., Walch, A., Ursini, F., Friedmann Angeli, J. P. \& Conrad, M. (2015). J. Biol. Chem. 290, 14668-14678.

Kabsch, W. (2010). Acta Cryst. D66, 125-132.

Koh, C. S., Didierjean, C., Navrot, N., Panjikar, S., Mulliert, G., Rouhier, N., Jacquot, J.-P., Aubry, A., Shawkataly, O. \& Corbier, C. (2007). J. Mol. Biol. 370, 512-529.

Kozin, M. B. \& Svergun, D. I. (2001). J. Appl. Cryst. 34, 33-41.

Krissinel, E. \& Henrick, K. (2004). Acta Cryst. D60, 2256-2268.

Laskowski, R. A., MacArthur, M. W., Moss, D. S. \& Thornton, J. M. (1993). J. Appl. Cryst. 26, 283-291.

Loria, J. P., Berlow, R. B. \& Watt, E. D. (2008). Acc. Chem. Res. 41, 214-221.

Maiorino, M., Aumann, K. D., Brigelius-Flohé, R., Doria, D., van den Heuvel, J., McCarthy, J., Roveri, A., Ursini, F. \& Flohé, L. (1995). Biol. Chem. Hoppe Seyler, 376, 651-660.

Morin, A., Eisenbraun, B., Key, J., Sanschagrin, P. C., Timony, M. A., Ottaviano, M. \& Sliz, P. (2013). Elife, 2, e01456.

Murshudov, G. N., Skubák, P., Lebedev, A. A., Pannu, N. S., Steiner, R. A., Nicholls, R. A., Winn, M. D., Long, F. \& Vagin, A. A. (2011). Acta Cryst. D67, 355-367.

Nomura, K., Imai, H., Koumura, T., Arai, M. \& Nakagawa, Y. (1999). J. Biol. Chem. 274, 29294-29302.

Sattler, W., Maiorino, M. \& Stocker, R. (1994). Arch. Biochem. Biophys. 309, 214-221.

Scheerer, P., Borchert, A., Krauss, N., Wessner, H., Gerth, C., Höhne, W. \& Kuhn, H. (2007). Biochemistry, 46, 9041-9049.

Schnell, J. R., Dyson, H. J. \& Wright, P. E. (2004). Annu. Rev. Biophys. Biomol. Struct. 33, 119-140.

Seiler, A., Schneider, M., Förster, H., Roth, S., Wirth, E. K., Culmsee, C., Plesnila, N., Kremmer, E., Rådmark, O., Wurst, W., Bornkamm, G. W., Schweizer, U. \& Conrad, M. (2008). Cell Metab. 8, 237248.

Sengupta, A., Lichti, U. F., Carlson, B. A., Cataisson, C., Ryscavage, A. O., Mikulec, C., Conrad, M., Fischer, S. M., Hatfield, D. L. \& Yuspa, S. H. (2013). J. Invest. Dermatol. 133, 1731-1741.

Svergun, D. I. (1992). J. Appl. Cryst. 25, 495-503.

Thomas, J. P., Geiger, P. G., Maiorino, M., Ursini, F. \& Girotti, A. W. (1990). Biochim. Biophys. Acta, 1045, 252-260.

Toppo, S., Vanin, S., Bosello, V. \& Tosatto, S. C. (2008). Antioxid. Redox Signal. 10, 1501-1514.

Tosatto, S. C., Bosello, V., Fogolari, F., Mauri, P., Roveri, A., Toppo, S., Flohé, L., Ursini, F. \& Maiorino, M. (2008). Antioxid. Redox Signal. 10, 1515-1526.

Ursini, F., Heim, S., Kiess, M., Maiorino, M., Roveri, A., Wissing, J. \& Flohé, L. (1999). Science, 285, 1393-1396.

Ursini, F., Maiorino, M., Valente, M., Ferri, L. \& Gregolin, C. (1982). Biochim. Biophys. Acta, 710, 197-211. 
Vagin, A. \& Teplyakov, A. (2010). Acta Cryst. D66, 22-25.

Winn, M. D. et al. (2011). Acta Cryst. D67, 235-242.

Winn, M. D., Isupov, M. N. \& Murshudov, G. N. (2001). Acta Cryst. D57, 122-133.

Wirth, E. K., Conrad, M., Winterer, J., Wozny, C., Carlson, B. A., Roth, S., Schmitz, D., Bornkamm, G. W., Coppola, V., Tessarollo, L., Schomburg, L., Köhrle, J., Hatfield, D. L. \& Schweizer, U. (2010). FASEB J. 24, 844-852.
Wortmann, M., Schneider, M., Pircher, J., Hellfritsch, J., Aichler, M., Vegi, N., Kölle, P., Kuhlencordt, P., Walch, A., Pohl, U., Bornkamm, G. W., Conrad, M. \& Beck, H. (2013). Circ. Res. 113, 408417.

Yang, W. S., SriRamaratnam, R., Welsch, M. E., Shimada, K., Skouta, R., Viswanathan, V. S., Cheah, J. H., Clemons, P. A., Shamji, A. F., Clish, C. B., Brown, L. M., Girotti, A. W., Cornish, V. W., Schreiber, S. L. \& Stockwell, B. R. (2014). Cell, 156, 317-331. 